Volume $50 \cdot$ Number $5 \cdot 2013$

\title{
COMMENTARY ON TROEDSSON'S 1964 ARTICLE "STUMP ARTERIAL CIRCULATION AND ITS RELATIONSHIP TO THE PRESCRIPTION OF A PROSTHESIS FOR THE GERIATRIC PATIENT"
}

\author{
JOAN E. SANDERS, PHD
}

$\Gamma$ /hough the reasons for amputation since 1964 have shifted from primarily disease (93\% disease, $5 \%$ trauma) [1] to a closer balance between disease and trauma (55\% disease, $45 \%$ trauma) [2], a major challenge faced by the amputation surgeon continues to be selection of the appropriate level of amputation.

Troedsson recognized the need for an instrument to estimate residual-limb circulation so as to facilitate decisions about amputation level [3]. The oscillometer, a device that measures peak pressure pulse in a segment upon slow release of a blood pressure cuff on the limb, was showing great promise. However, no subsequent reports in the literature demonstrate that oscillometry was developed into a highly effective tool for amputation-level selection. Numerous other instruments were pursued, and today, a number of techniques are used, including angiography, segmental limb pressure assessment, thermography, fluoroscopy, skin blood flow using laser Doppler or radioisotope washout techniques, and transcutaneous oxygen pressure [4]. Though these techniques have dramatically facilitated decision-making surrounding limb-salvage procedures to avoid amputation, none has been adopted as a definitive technique to indicate appropriate amputation level.

One reason no single instrument is effective for selecting amputation level is that many aspects of vascular function affect tissue viability. Each instrument measures a single aspect of vascular health. For example, oscillometers measure arterial distensibility, an important measure because stiff arteries tend to occlude and limit nutrient delivery. Skin blood flow rate and limb arterial blood pressure are also factors, but a patient can have good blood flow and adequate limb arterial pressure but a poor capability to transport nutrients into tissues because vessel walls are stiff and structurally difficult to penetrate. Further challenges are that some patients' tissues adapt well to amputation while others' do not. Thus, data collected before the amputation may or may not indicate tissue health postamputation. A current challenge for the research community is the development of tools to synthesize quantitative measurements from instruments with clinical insight and experience to help decide amputation level.

Many instruments have improved postamputation care. These include sensors and controllers integrated into powered componentry, as well as measurement instruments used to make computer-manufactured sockets. An exciting future prospect is the use of on-board monitoring and communication devices not only to provide important information to practitioners to match prosthesis design to patient needs but also to facilitate communication between the patient, his or her prosthesis, and the practitioner.

\section{REFERENCES}

1. Glattly HW. A statistical study of 12,000 new amputees. South Med J. 1964;57:1373-78. [PMID:14195964]

2. Ziegler-Graham K, MacKenzie EJ, Ephraim PL, Travison TG, Brookmeyer R. Estimating the prevalence of limb loss in the United States: 2005 to 2050. Arch Phys Med Rehabil. 2008;89(3):422-29. [PMID:18295618]

3. Troedsson BS. Stump arterial circulation and its relationship to the prescription of a prosthesis for the geriatric patient. Bull Prosthet Res. 1964;10(2):39-53.

4. Bowker HK, Michael JW, editors. Atlas of limb prosthetics: Surgical, prosthetic, and rehabilitation principles. Rosemont (IL): American Academy of Orthopedic Surgeons; 2002.

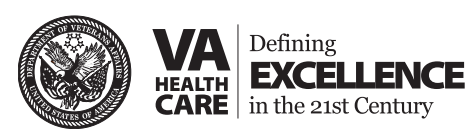

